\title{
PSYCHE
}

\begin{tabular}{lll}
\hline Vol. 99 & 1992 & No. 1 \\
\hline
\end{tabular}

\section{EUXOA AUXILIARIS: A MOTH THAT SPRAYS ${ }^{1}$}

\author{
By Thomas Eisner and Maria EISNer \\ Section of Neurobiology \& Behavior \\ W347 Mudd Hall, Cornell University \\ Ithaca, NY 14853-2702
}

The phenomenon we here describe was discovered by serendipity. It was early May 1991, and we were staying in a rented cottage in Portal, Arizona, at the entrance of Cave Creek Canyon in the Chiricahua Mountains. We were reading in bed at night when one of us suddenly felt what was unmistakably a dousing of spray in the face. The fluid was odorless and evoked neither itch nor pain. We suspected an insect, but none was in sight of a kind known to discharge defensive fluids. However, we did note an inordinate number of moths in the cottage at the time, all seemingly of one species, which we thought might have gained entrance through an improperly closed door after dark, drawn to the light indoors (Fig. 1 , top). It occurred to us that we might have inadvertently touched one of these moths, perhaps a recently emerged individual, and that we had been sprayed with meconial fluid. But we dismissed the notion and went to sleep.

The next morning we were again sprayed, this time each of us separately as we exited through the cottage's glass-paneled sliding doors. The same kind of moth we had noted inside our quarters was also hiding in numbers within the two parallel grooves of the upper railings of the doors. Each time one or the other door was

\footnotetext{
${ }^{1}$ Paper no. 111 of the series Defense Mechanisms of Arthropods; no. 110 is Eisner and Eisner, Psyche (in press). We dedicate this paper affectionately to William L. Brown, Jr., close friend, teacher, and best of colleagues. Manuscript received 16 March 1992.
} 

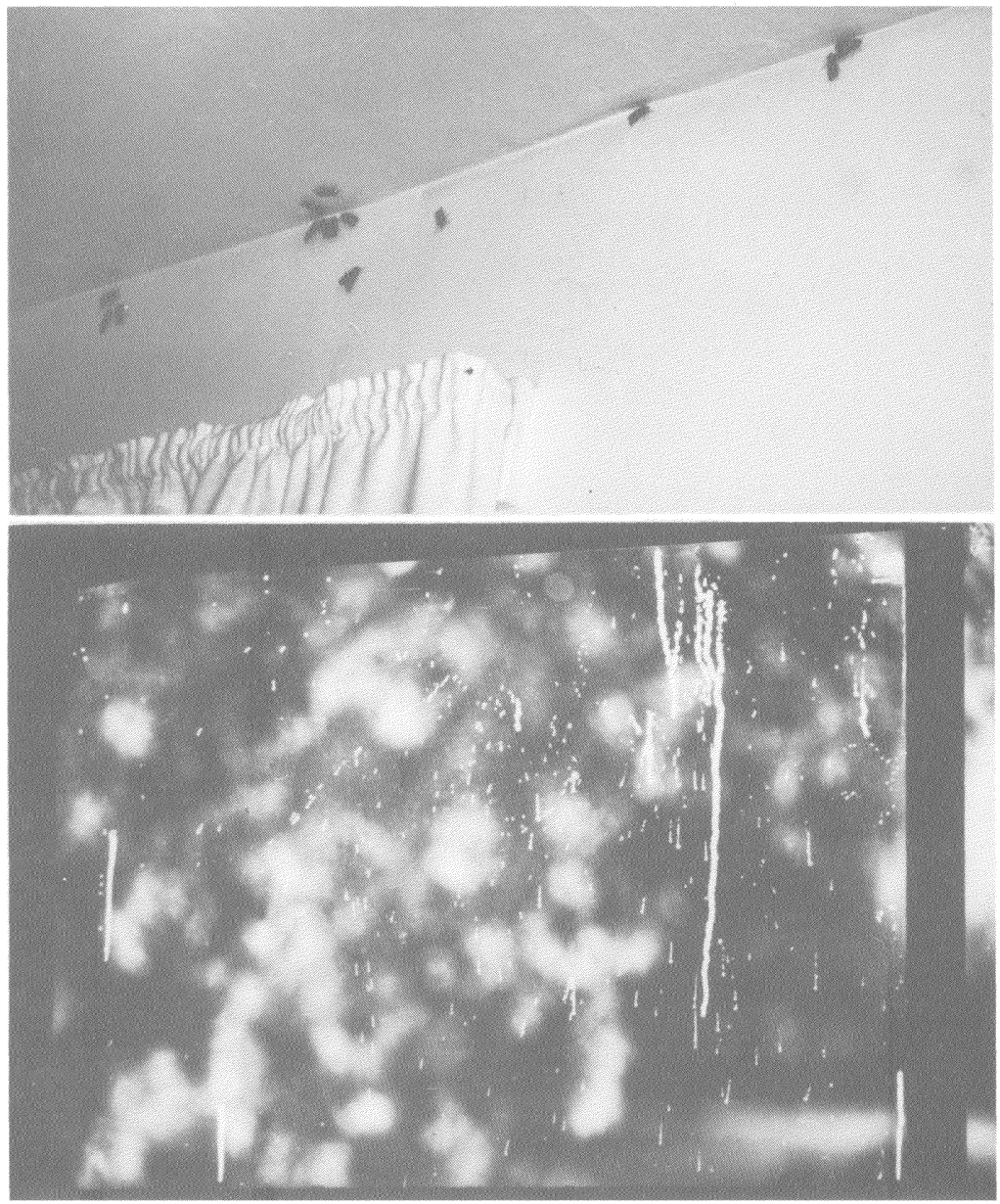

Fig. 1. (Top) E. auxiliaris at rest on wall of cottage, Portal, Arizona. (Bottom) Spray patterns left by moths on glass of sliding door of cottage.

slid open, the moths in the corresponding groove were physically dislodged, and they were responding to the disturbance by spraying. We could verify this visually. The moment a moth came to be prodded by a door, it sprayed and took to flight. The discharges were substantial and left distinct markings on the paneling of the doors (Fig. 1, bottom). The phenomenon was new to us, but not to 
our hostess, who had come to regard the springtime visitation of moths and soiling of her doors as a recurring annoyance.

Many moths are known to be chemically protected, either by systemic factors, or by surface effluents such as froths or oozings. None were known to eject glandular sprays, as so many beetles do. Our moth proved to be no exception. We found it to eject its spray from the anus, confirming our initial suspicion that the fluid was of enteric origin. We here describe what we were able to learn about this moth, which turned out to be the familiar army cutworm, Euxoa auxiliaris, a member of the Noctuidae (Fig. 2). Regrettably, our findings are preliminary. We report them because we do not know whether we will again be able to study. the moth.

E. auxiliaris occurs in the Great Plains from Canada to Mexico. The larva is a frequent pest of crops in many western states (Hardwick 1970). The moth is a seasonal migrant. In early summer, after adult emergence, it flies to higher elevations. It returns to lower elevations in the fall, where the females oviposit. In the southern portion of its range it is on the wing in early spring and fall, and aestivates in the mountains. Its behavior during aestivation appears not to be fully understood. Although there is certainty that the moths do not breed during summer, they do feed during that time

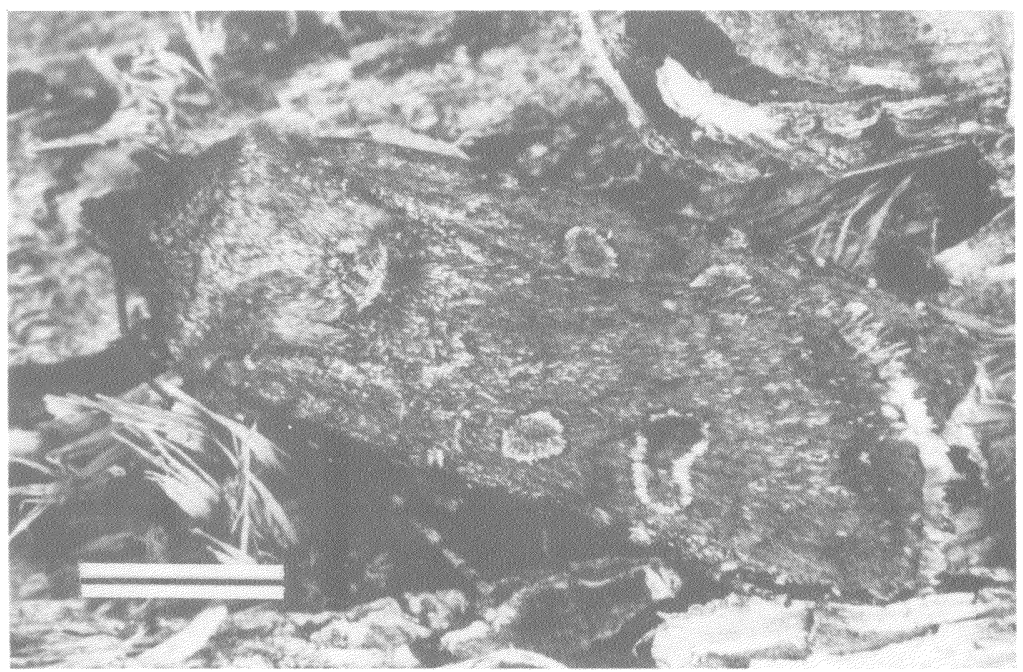

Fig. 2. Euxoa auxiliaris. Reference bar $=5 \mathrm{~mm}$. 
(they have been noted in Montana in midsummer, in alpine meadows, visiting flowers at dusk), and appear to gain in fat body reserves (Chapman et al. 1955; Pruess 1967). Some of the moths, or perhaps all at one time or other, may seek shelter during aestivation. In Alberta, for instance, inactive adults have been reported to stay in buildings throughout the summer (Seamans 1929).

Laboratory tests have shown the moths to be capable of high flight performance. Individuals tethered to the rotating arm of a flight machine, if given honey-water beforehand, commonly flew upward of 50 miles. One individual flew uninterruptedly for over 23 hours at a mean speed of $5.8 \mathrm{miles} / \mathrm{hr}$ for a distance of 133 miles (Koerwitz and Pruess 1964).

Interesting observations have been made concerning retention of the meconium in this moth. Pruess (1967) mentions that the meconium is not voided immediately after emergence but "over a period of 1 or 2 days" or "perhaps slightly longer under weather conditions unfavorable for activity." He does not specify the circumstances under which the meconium is voided, or whether its elimination can be triggered by stimulation of the moth. However, he does give data, based on examination of thousands of lighttrapped individuals from a series of locations ranging westward from Nebraska to Wyoming, which indicate that during the spring flight period there is a general trend for the proportion of moths possessing the meconium to decline from east to west. He concluded from this that western individuals are eastern ones on the move, and that the moth does indeed migrate westward in the spring.

Based on this information, the moths in our cottage are likely to have been spring migrants, newly arrived from lower elevations. Portal is at substantial elevation (4700 feet), high enough and cool enough, it would seem, to serve as an appropriate aestivation site for the moth. Specimens of both sexes that we dissected proved to be reproductively immature, as spring migrants of the species were known to be (Pruess 1967). We found the ovaries of females to contain no mature eggs.

As days passed we noted that although many nocturnal insects were abundant at the time, E auxiliaris was virtually the only species finding its way into our quarters in numbers. We checked carefully and found that open doors or faulty screening could not 
have provided the gates of access. Most likely, the moths were entering through the tortuous ducts of the air conditioning system (not operating at the time), an indication possibly that they were seeking well concealed rather than openly accessible shelter. We wondered whether they were entering for overnight stays or longer. The moths were quiescent by day (they tended to rest behind curtains or in other secluded places) but relatively active by night (they then tended to rest in the open as seen in Fig. 2, top, and be prone to take to flight when disturbed). Given the opportunity, we concluded, they would have opted for evening departure. By mid-May moth arrival declined, and it came to a halt by the end of the month. We estimate that over the period of our stay (May 3-June 3) well over 300 moths must have entered our cottage. We experimented with several dozens of them.

Simple observations confirmed that the moths eject their spray in response to disturbance. Catching individuals by placing vials over them as they rested on walls caused them almost invariably to discharge into the vials. Those that initially failed to spray usually did so if their vial was subsequently given a strong tap. As indicated by the pattern of droplets on the vial wall (Fig. 3, bottom left), the fluid is discharged as a coarsely rather than finely dispersed spray. The liquid varied considerably in clarity. While it was virtually translucent in some cases, it was turbid, or irregularly laden with particulate matter, in most (Fig. 3, bottom right). Ejection was also elicited by direct contact of the moths. Individuals that we touched as they rested on walls usually sprayed and took to flight.

The volumes ejected by the moths were considerable. We measured such volumes by capturing moths in vials and taking up in calibrated microcapillary tubes the fluid they discharged onto the vial walls. Samples of single sprayings thus collected from 18 individuals measured $10.2 \pm 6.7 \mu \mathrm{l}(\mathrm{x} \pm \mathrm{SD})($ range $=3-22 \mu \mathrm{l})$. Assuming a density of 1.0 for the fluid, this amounts on average to $5.4 \%$ of moth body mass [mass $=188 \pm 47 \mathrm{mg}(\mathrm{x} \pm \mathrm{SD})$, range $=$ $110-290 \mathrm{mg}$, based on $\mathrm{N}=10$ moths].

We expected the spray to stem from the rectum. Dissection of both males and females revealed this organ to be a capacious sac (Fig. 3, top), which we found to be empty in individuals that had 

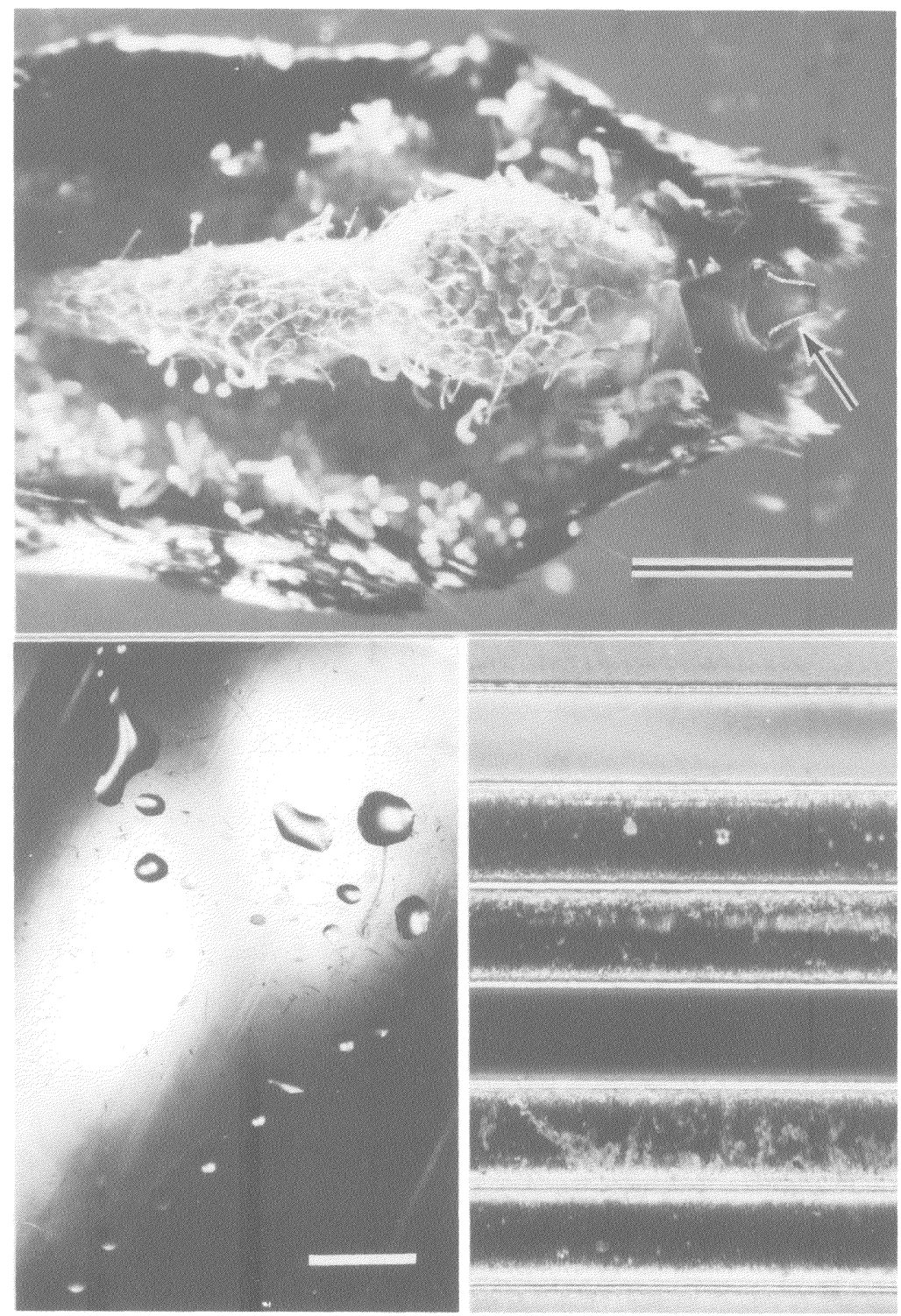
just sprayed, and full in those we had coaxed gently into vials without inducing ejections, and killed by refrigeration.

Individuals that had ejected once were usually unable to spray a second time immediately thereafter. However, they seemed to regain their capacity to discharge if they were confined for some time with access to water. To check more precisely on this ability, 20 individuals that had been taken freshly from the walls one evening were stimulated at 16,58 , and $82 \mathrm{hr}$ after capture. They were maintained singly in vials over that period with only water (offered on wads of cotton), and at the given intervals were transferred to a small fenced enclosure, where they came to rest horizontally and were stimulated by having a leg pinched with forceps. Discharges were always visually apparent and were scored when they occurred (the transfer of the moths from vial to enclosure was effected by gentle prodding without causing the moths to spray). The results (Fig. 4) show that, given only water, the moths can indeed regain the capacity to discharge after ejection. The meconium might thus be but the first of numbers of rectal loads that the moths are capable of expelling.

An incidental observation was that the moths always directed their discharges posteriorly. Individuals that were stimulated by pinching of a leg never sprayed directly toward that leg. The anal turret (Fig. 3, top) through which the spray is ejected is evidently not an aiming device.

Although we have no direct evidence, we suspect the spray of $E$. auxiliaris to be defensive. We transported a few specimens back live to our Cornell laboratories, where only one survived long enough to be checked for palatability in a test with a wood thrush (Hylocichla mustelina). The caged bird, which over time had been fed a number of different insects and often rejected those that were

Fig 3. (Top) Dissected abdomen of male E. auxiliaris, showing rectal sac from which spray is ejected. Arrow denotes anal turret. Large quantities of fat body were removed to expose the sac. (Bottom left) Pattern of spray droplets left on wall of vial in which a moth was induced to discharge. (Bottom right) Parallel array of microcapillary tubes $(1.5 \mathrm{~mm}$ outer diameter $)$, laden with discharged fluid from individual moths. Note variability in turbidity and particulate content. Reference bars: top $=2 \mathrm{~mm}$; bottom left $=5 \mathrm{~mm}$. 


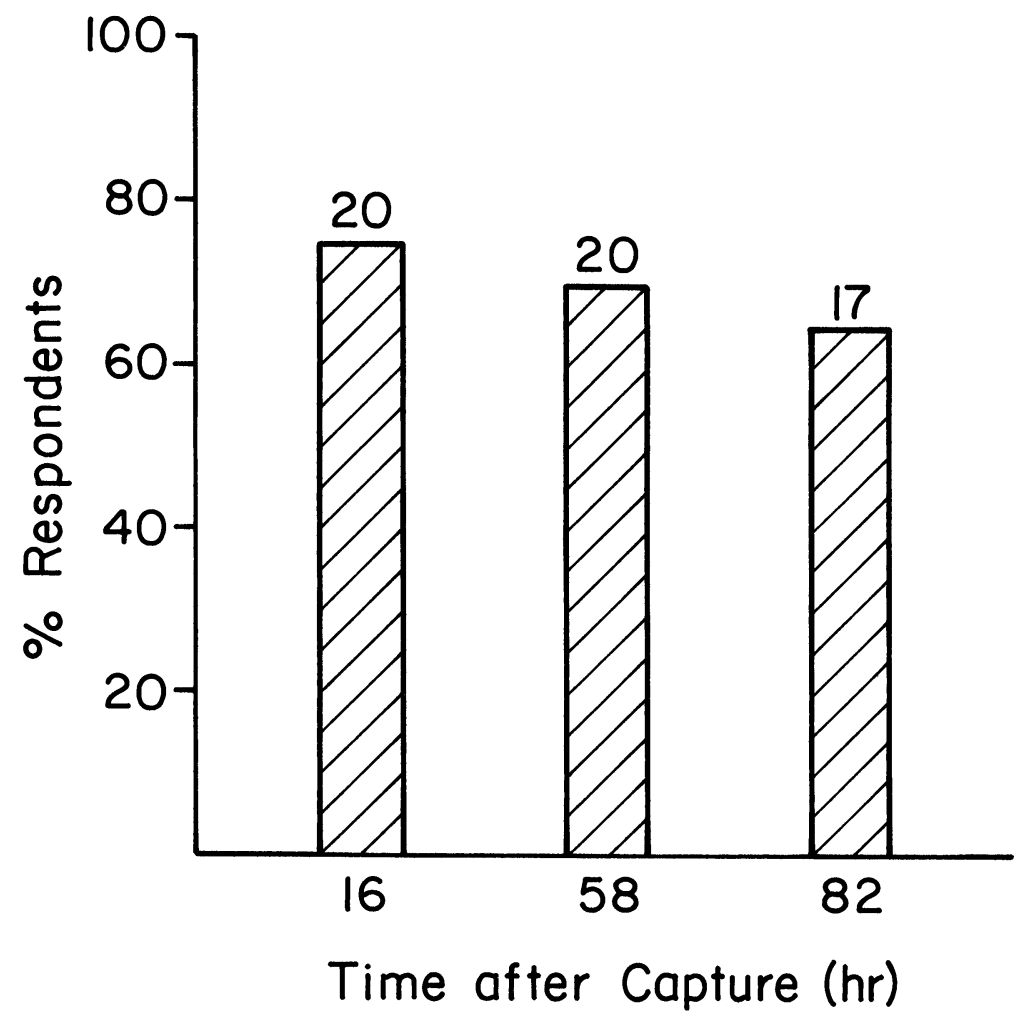

Fig 4. Incidence of spraying in 20 E. auxiliaris, plotted as a function of time after capture. The moths were stimulated at the times shown, by pinching an individual leg with forceps. Between stimulations the moths were given access to water only. The reduced sample size at $82 \mathrm{hr}$ reflects loss of 3 individuals to death.

chemically protected, pursued the fluttering moth the moment it was offered, caught it, and ate it.

In some ways, admittedly, the moth's effluent appears ill-suited for defense. It is in no obvious way chemically noxious: it is odorless, mildly acidic (a pooled sample from several moths, obtained some weeks beforehand but kept refrigerated, had a $\mathrm{pH}$ of 5.0-5.5), topically non-irritant (application to a small open skin lesion proved painless), and seemingly devoid of major volatile organic components (as revealed by gas chromatography of an ether extract). 
Could the spray effect its deterrence by startling? Might it thus act, say, against orb-weaving spiders when migrating moths become entrapped in webs? Or against ants, scorpions, or rodents when the moths are in temporary shelter? Do the moths ever cluster densely during migratory stopovers, or during resting periods at aestivation sites, and do they then discharge collectively when attacked?

One also wonders whether the moths might resort to spraying when pursued or caught by bats during migration or crepuscular foraging. To check whether they are responsive to the echolocating chirps of bats, pulses of an ultrasonic frequency were delivered with an electronic instrument ${ }^{2}$, hand-held at various distances $(0.05-2 \mathrm{~m})$ from moths resting on our cottage walls. None of the moths thus stimulated sprayed, took to flight, or even visibly moved. Given the unnatural setting and that the moths were not in flight, we are reluctant to draw definitive conclusions from this result. E. auxiliaris does have the thoracic tympanic organs characteristic of noctuids, and presumably therefore the capacity to detect bat sounds. In tethered flight, moths have been noted to accelerate when stimulated by sound (Koerwitz and Pruess 1964).

Other questions remain open as well. Where does E. auxiliaris obtain the fluid it might eject subsequent to the initial meconial discharge? Does it drink from open water sources by "puddling," as so many Lepidoptera do to secure ionic sodium (Arms et al. 1974; Pivnick \& McNeil 1987), and should its discharge mechanism (specifically its ability to load and discharge repeatedly for purposes of defense) be viewed as a secondary specialization that evolved from puddling? Could rectal loading also provide the migratory moth with water? And what happens at high altitude during summer? Do the moths then no longer spray? Oddly, they have at least one known enemy at that time. Chapman et al. (1955) reported finding densely packed remains of E. auxiliaris in the fecal droppings of grizzly bears at a site in Montana. Whether the bears locate the moths by tracking down their aggregations, and whether they are the only predators to do so, remains unknown.

2 Electronic Tape Measure (Radio Shack cat. no. 64-2;830), pulse characteristics: $0.6 \mathrm{~ms}, 45 \mathrm{kHz}, 108 \mathrm{~dB}$ Sound Pressure Level peak-to-peak at $1 \mathrm{~m}$ (reference $0 \mathrm{~dB}$ $=2310-5 \mathrm{~Pa})$. 
A number of noctuid moths closely related to E. auxiliaris are also seasonal migrants. Thus, Agrotis ypsilon, a species of almost world-wide distribution, is known in Egypt and India to migrate to cool regions in the spring (Kapur 1955; Williams 1930). Best documented (Common 1954) is the migration of Agrotis infusa in Australia, the so-called bogong moth, which forms large summer aggregations in rock crevices and small caves at altitudes above $4000 \mathrm{ft}$ in the Australian Alps. A. infusa emits "drops of excrement" when disturbed. The fluid is said to be of sweet odor at the beginning of aestivation, but to become "particularly offensive" toward the end of summer. The amount of fluid emitted by the moths appeared to be a function of moisture available. After a 2-3 week dry spell, the moths scarcely excreted when disturbed; following rain, their output became copious again. Common presents no evidence that the effluent serves in defense. However, such predation as he noted (by crows, currawongs, fox) appeared to be of lesser importance. In its aggregations, the moth is also known to be eaten by aborigines.

\section{ACKNOWLEDGEMENTS}

We thank our hostess in Portal, Mrs. Mary Willy, for numerous kindnesses, our colleague John Franclemont for identifying the moth and much help with the literature, E. Mitchell Masters of Ohio State University, Columbus, for loan and calibration of the electronic range finder, and our associate Athula Attygalle for the $\mathrm{pH}$ measurement and gas chromatographic analysis. Our colleague Scott Smedley commented on the manuscript. Study supported in part by NIH grant AI-02908 and Hatch grant NYS-191402.

\section{Literature Cited}

Arms, K., P. FeEney, AND R. C. Lederhouse

1974. Sodium: stimulus for puddling behavior by tiger swallowtail butterflies, Papilio glaucus. Science 185: 372-374.

Chapman, J. A., J. I. ROMER, AND J. STARK

1955. Ladybird beetles and army cutworm adults as food for grizzly bears in Montana. Ecology 36: 156-158.

CoMmon, I. F. B.

1954. A study of the ecology of the adult bogong moth Agrotis infusa (Boisd.) (Lepidoptera: Noctuidae), with special reference to its behavior during migration and aestivation. Austral. Jour. Zool. 2: 223-263. 
HARDWICK, D. F.

1970. The genus Euxoa (Lepidoptera: Noctuidae) in North America. 1. Subgenera Orosagrotis, Longivesica, Chorizagrotis, Pleonectopoda, and Crassivesica. Memoires Entomol. Soc. Canada No. 67, 175 pp.

KAPUR, A. P.

1955. On moths of the greasy cutworm - Agrotis ypsilon Rott. found dead in numbers on snow over Rohtang Pass, N.W. Himalayas. Ind. Jour. Entomol. 17: 289-294.

Koerwitz, F. L., AND K. P. Pruess

1964. Migratory potential of the army cutworm. Jour. Kansas Entomol. Soc. 37: 234-239.

Pivnick, N. A., AND J. M. MCNeIL

1987. Puddling in butterflies: sodium affects reproductive success in Thymelicus lineola. Physiol. Entomol. 12: 461-472.

PRUESS, K. P.

1967. Migration of the army cutworm, Chorizagrotis auxiliaris (Lepidoptera: Noctuidae). I. Evidence for a migration. Ann. Entomol. Soc. Amer. 60: 910-920.

Seamans, H. L.

1929. The army cutworm. Canada Dept. Agric., Pamphlet no. 102, 8 pp. WILLIAMS, C. B.

1930. The Migration of Butterflies; 473 pp. (Oliver and Boyd, Edinburgh). 

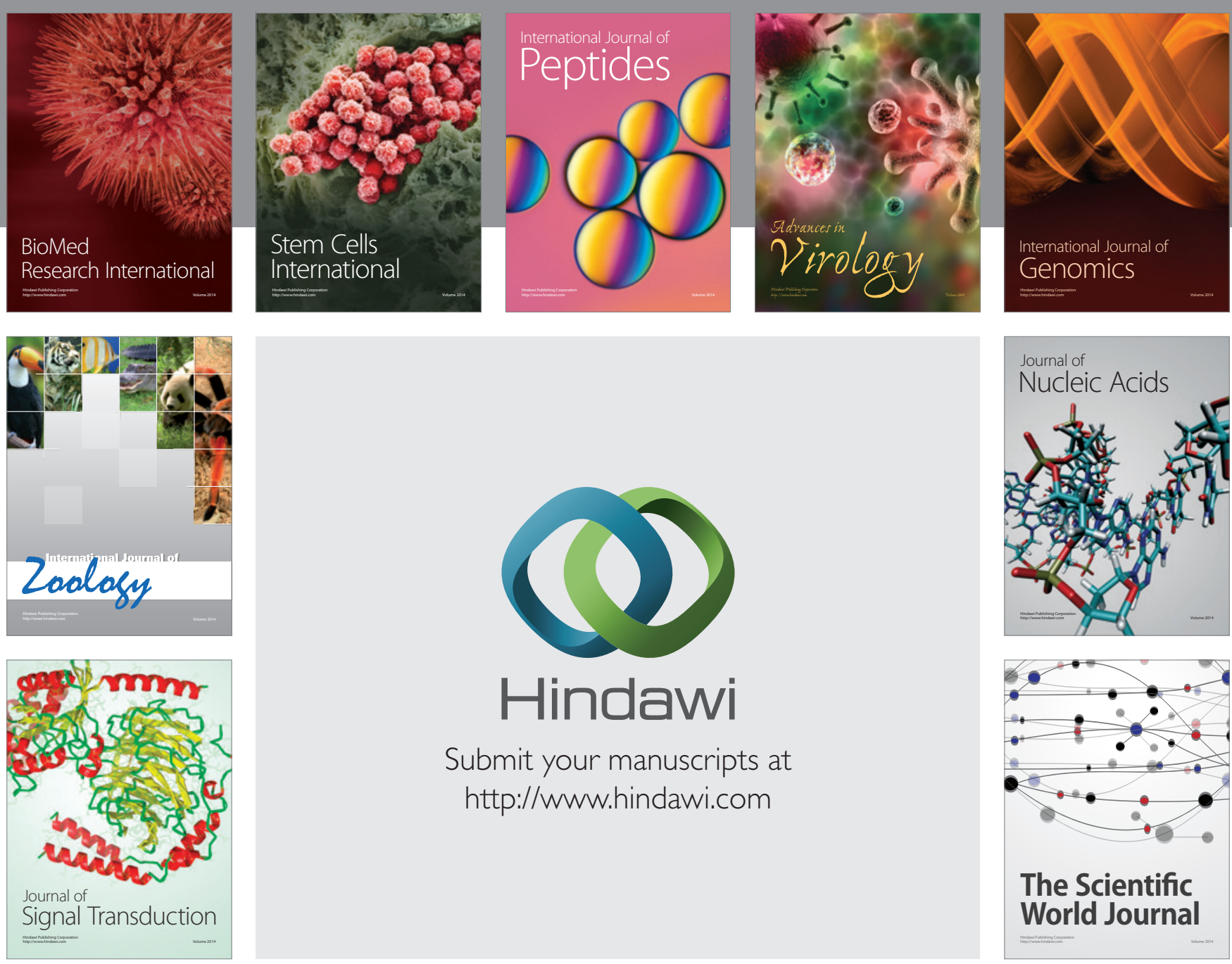

Submit your manuscripts at

http://www.hindawi.com
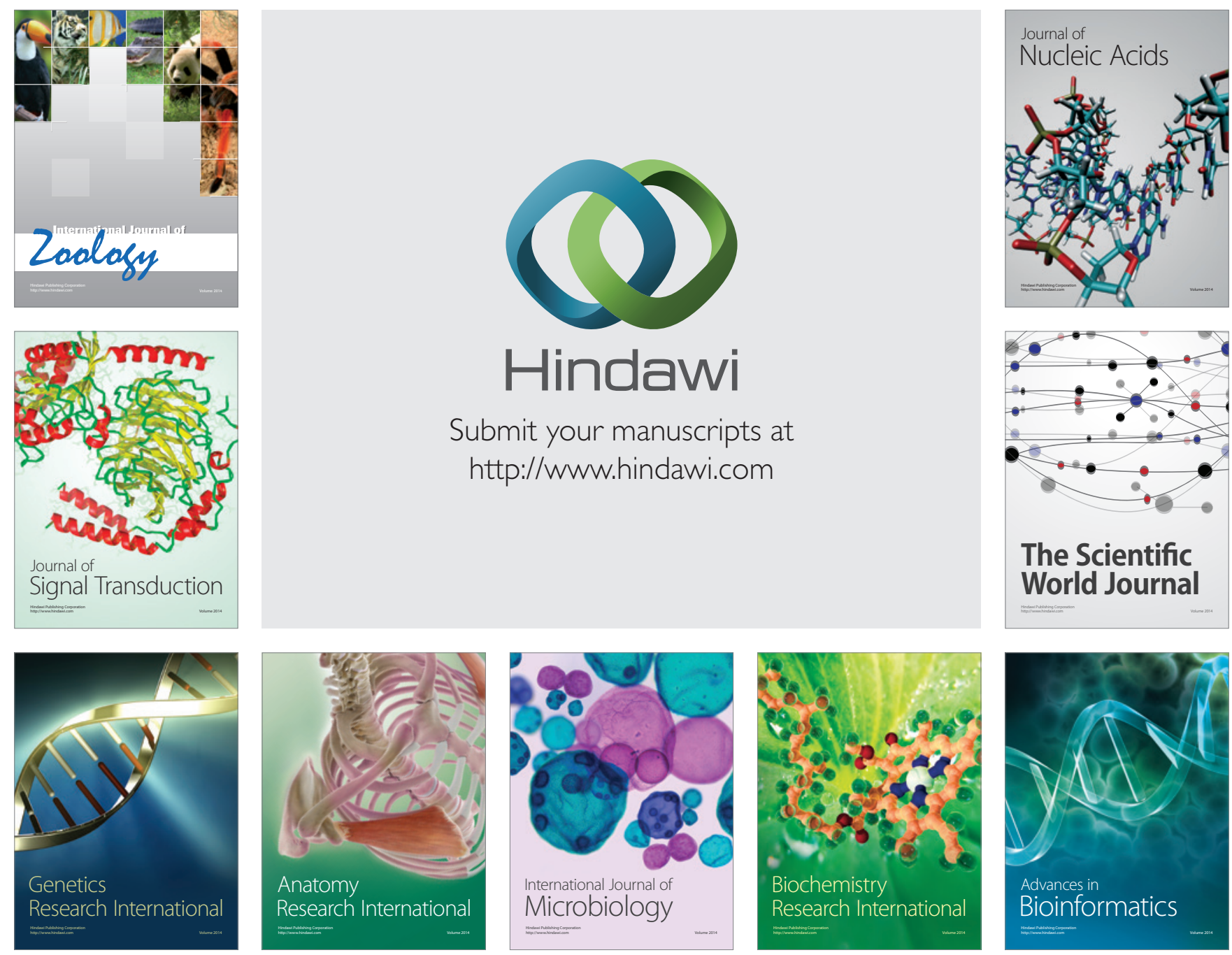

The Scientific World Journal
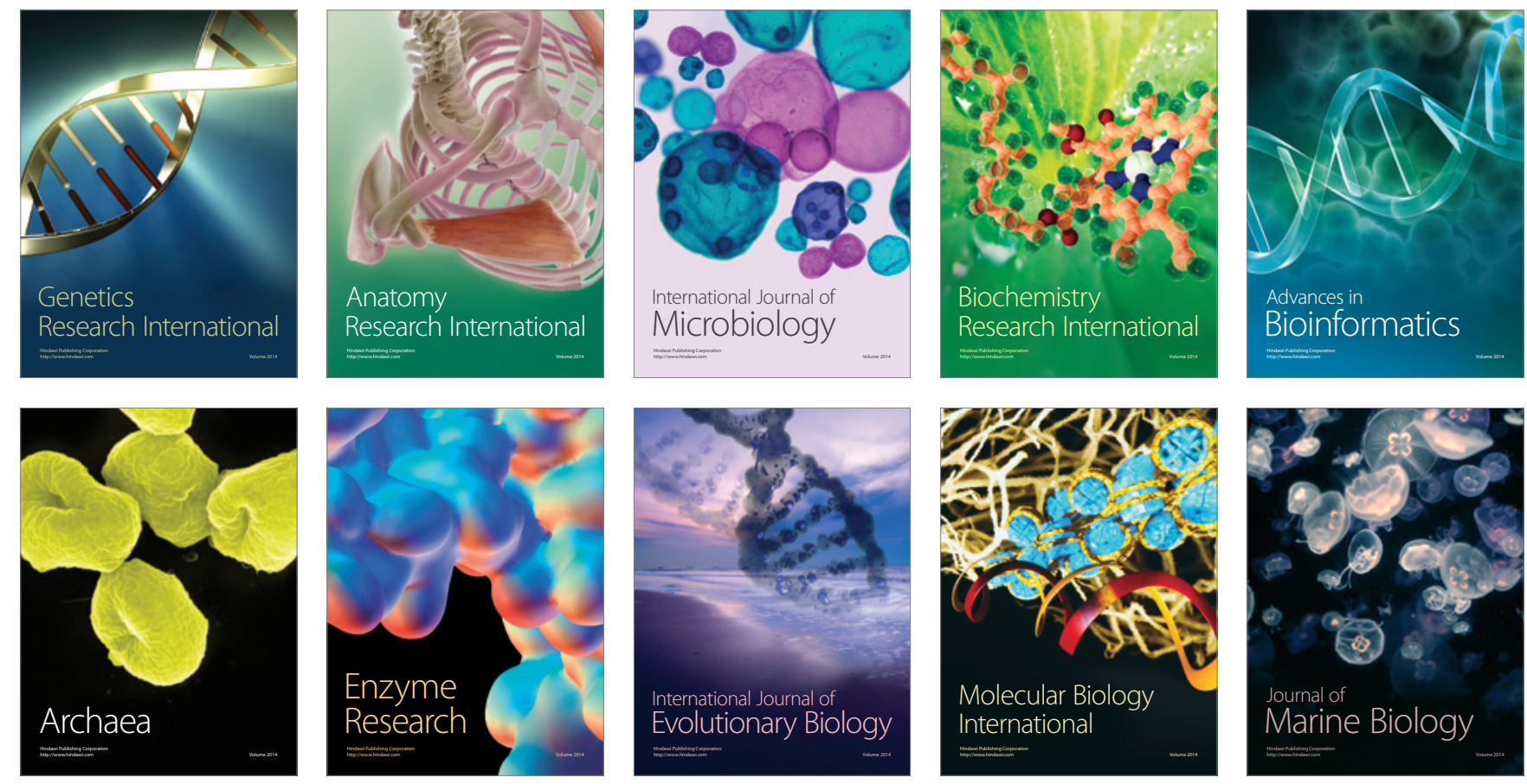